\section{KẾT LUẬN}

Qua nghiên cứu 47 bệnh nhân tại bệnh viện đa khoa tỉnh Hà Tĩnh, chúng tôi nhận thấy kỹ thuật cấy MTNTVV 2 buồng bước đầu triển khai thành công, là một phương pháp điều trị an toàn, hiệu quả, ít nguy hiểm với tỉ lệ biến chứng thấp. Sự thành công này góp phần tiết kiệm thời gian và chi phí điều trị cho bệnh nhân, qua đó làm giảm tải cho các bệnh viện tuyến trên.

\section{TÀI LIÊU THAM KHẢO}

1. Prystonsky, E.N., Cardiac Arrhythmias. 1994

2. Parsonnet, V., et al., An intracardia bipolar electrode for interim treatment of complete heart block. Am J Cardiol, 1962. 10: p. 261-5.

3. Larsson, B., et al., Lessons from the first patient with an implanted pacemaker: 1958-2001. Pacing Clin Electrophysiol, 2003. 26(1 pt 1): p.114-24.
4. Nguyễn Mạnh Phan, et al., Khuyến cáo của Hội Tim Mạch học Việt Nam về chỉ định đặt máy tạo nhịp. K̇huyến cáo về các bệnh lý tim mạch và chuyển hóa, 2008: p.217-234.

5. Belott. PH. Implant Technique, Cardiac pacing for clinician Second Edition, Fred M. Kusumoto, 2008: p.116-255.

6. Nguyễn Sỹ Huyên, Trân Thống, Nguyễn Phú Du, Ta Tiến Phước, Máy tao nhip tim cơ bản thực hành, Tạp chí Tim mạch học Việt Nam số 16, 1998: p.60.

7. Pham Như Hùng, Trân Song Giang, Trân Văn Đồng, Tạ Tiến Phước, Thực trang câyy máy tạo nhịp tim vĩnh viễn 1 buồng và 2 buồng tim trong chỉ định nhip chậm tại Viện tim mạch Quốc gia Việt Nam. Kỷ yểu tóm tắt các báo cáo khoa học, Đại hội Tim mach toàn quốc lần thứ 13, 2012: p.19-20.

8. Trân Thhông, Tạo nhịp thất với máy 2 buồng: Lợi hay hại? Hội nghị Tim mạch miên nam, 2009.

\title{
ĐIỆN Đồ TĨNH MẠCH PHỔI Ở BỆNH NHÂN RUNG NHĨ KỊCH PHÁT
}

\section{Phan Đình Phong ${ }^{1}$, Bùi Văn Nhơnn, Trần Tuấn Việt ${ }^{1}$, Đỗ Mạnh Cầm ${ }^{1}$}

\section{TÓM TẮT}

Nghiên cứu được tiến hành với muc tiêu mô tả đăc điểm điện đồ tĩnh mạch phổi ở bệnh nhân rung nhî kịch phát tại Viện Tim mạch Việt Nam. Kết quá cho thấy, điện đồ tĩnh mạch phổi đều được ghi nhận ởbệnh nhân rung nhĩ kịch phát (chiếm 100\%). Khoảng thời gian dẫn truyền nhĩ - tĩnh mạch phổi (khoảng APV) tối đa và trung bình ở tĩnh mạch phổi trên trái là dài nhất $(67,00 \pm 9,72 \mathrm{~ms}$ và $56,65 \pm 8,52 \mathrm{~ms}$, tương ứng). Hình dạng điện đồ tĩnh mach phổi thường gặp là điện đồ nhiều thành phần $(31,6 \% \pm 8,7 \%)$; hình dạng điện đồ tĩnh mạch phổi khác bao gồm điện đồ 3 pha $(29,5 \% \pm 9,1 \%)$, điện đồ 2 pha $(19,4 \% \pm 8,4 \%)$ và điện đồ kép $(5,8 \% \pm 5,9 \%)$. Điện đồ kép gặp nhiêu nhất ở tĩnh mạch phổi trên trái $(11,9 \% \pm 6,8 \%)$.

Tư khoá: Rung nhĩ kịch phát, điện đồ tĩnh mạch phổi, điện đồ nhiều thành phần, điện đồ kép.

\section{SUMMARY \\ PULMONARY VEIN POTENTIALS IN \\ PATIENTS WITH PAROXYSMAL ATRIAL FIBRILLATION}

Objectives: To describe pulmonary vein (PV) potentials in patients with paroxysmal atrial fibrillation at the Vietnam Heart Institute. The results showed that typical PV potentials were recorded all patients

\footnotetext{
${ }^{1}$ Trường Đại học Y Hà Nội

${ }^{2}$ Bệnh viện Đại học Y Hà Nội

Chịu trách nhiệm chính: Bùi Văn Nhơn

Email: drbuinhon@hmu.edu.vn

Ngày nhận bài: 25/6/2021

Ngày phản biện khoa học: 25/7/2021

Ngày duyệt bài 15/8/2021
}

withparoxysmal atrial fibrillation(100\%). The maximal and mean A-PV intervals in left superior pulmonary vein were longest $(67.00 \pm 9.72 \mathrm{~ms}$ và $56.65 \pm 8.52$ $\mathrm{ms}$, respectively).Types of pulmonary vein potentials were a higher prevalence ofmultiphasic $(31.6 \% \pm$ $8.7 \%)$; the others were included triphasic potentials $(29,5 \% \pm 9,1 \%)$, biphasic potentials $(19,4 \% \pm 8,4 \%)$, and double potentials was $5.8 \% \pm 5.9 \%$. The double potentials was a highest in left superior pulmonary vein $(11.9 \% \pm 6.8 \%)$

\section{Keywords:}

Paroxysmal atrial fibrillation,pulmonary vein potentials, multiphasic potentials, double potentials.

\section{I. ĐĂT VẤN ĐỀ}

Rung nhĩ là rối loạn nhịp tim thường gặp, xảy ra ở 1-2\% dân số. Tỷ lệ mới mắc và hiện mắc rung nhĩ có xu hướng cao ở các nước phát triển [1]. Tỷ lệ rung nhĩ kịch phát ước tính chiếm 3\% ở người trên 20 tuổi; tỉ lệ tăng cao ở người lớn tuổi và những bệnh nhấn mắc các bệnh như tăng huyết áp, suy tim, bệnh động mạch vành, bệnh lý van tim, béo phì, đái tháo đường, bệnh thận mạn tính [1]. Trung bình tỷ lệ mắc mới của rung nhĩ khoảng $0,1 \%$ mỗi năm ở người dưới 40 tuổi, và tăng lên nhanh ở người trên 60 tuổi với 1,5-2,0\% [2]. Theo nghiên cứu Framingham, tỷ lệ hiên mắc rung nhĩ từ 0,5\% ở tuổi 50-59 tăng nhanh tới 8,8\% ở tuổi 80-89. Tỷ lệ mắc rung nhĩ kịch phát trong số rung nhĩ là cao: theo Godfredsen là 35,0\%, theo Takahashi là 40,2\%, theo Phillips là 62,0\%. Cùng với xu hướng gia tăng tỷ lệ mắc thì gánh nặng của rung nhĩ cũng 
tăng nhanh chóng [1]. Rung nhĩ có thể gây những biến chứng nặng nề.

Rung nhĩ làm tăng tỷ lệ suy tim và đột quy, là yếu tố nguy cơ độc lập của đột quy. và là nguyên nhân gây ra $18-25 \%$ nhồi máu não. Ở bệnh nhân đột quy, tỷ lệ rung nhĩ kịch phát được phát hiện rất cao với 36,0\% [3].

Tĩnh mạch phổi có vai trò trung tâm trong quá trình sinh lý bệnh của rung nhĩ. Nhiều nghiên cứu đã chỉ ra các ổ ngoại vị ở tĩnh mạch phổi có thể là trung tâm khởi phát gây ra rung nhĩ. Nguî̀n gốc chính của các ổ ngoại vị là do các bó/bè cơ tim nhĩ trái chạy sâu và lát trên bề mặt tĩnh mạch phổi. Các bó/bè cơ này bao gồm chủ yếu là các tế bào cơ rất giống với tế bào cơ nhĩ bình thường, và sự xuất hiện các tế bào cơ này thường nằm rải rác ở các bó/bè cơ tim trong tĩnh mạch phổi. Rung nhĩ kịch phát thường có nguồn gốc từ bó/bè cơ tim kéo dài trong tînh mạch phổi. Một số nghiên cứu cho thấy, tĩnh mạch phổi không chỉ hoạt động như ổ khởi phát rung nhĩ mà còn tham gia vào duy trì rung nhĩ [4]. Tác giả Wendel Moreira và cộng sự tiến hành nghiên cứu ở 70 bệnh nhân rung nhĩ kịch phát, kết quả đã phát hiện hầu hết các ổ khởi phát rung nhĩ là từ tĩnh mạch phổi. Hoạt động điện ở tĩnh mạch phổi trên trái được phát hiện ở 63 bệnh nhân chiếm tỷ lệ $90,0 \%$, ở tĩnh mạch phổi dưới trái là 52 bệnh nhân chiếm 74,3\%, ở tĩnh mạch phổi trên phải là 57 bệnh nhân chiếm $81,4 \%$ và ở tĩnh mạch phổi dưới phải là 16 bệnh nhân chiếm 22,9\% [5]. Hiểu biết chính xác về điện đồ của các tĩnh mạch phổi góp phần tăng hiệu quả triệt đốt rung nhĩ kịch phát thành công, đồng thời tránh được các biến chứng sau can thiệp như hẹp tĩnh mạch phổi sau thủ thuật, biến cố về huyết khối hoặc tổn thương dây thần kinh...

Tại Việt Nam, hiện nay chưa có nhiềunghiên cứu về đặc điểm điện đồ ở tĩnh mạch phổi, đặc biệt là ở bệnh nhân rung nhĩ kịch phát. Do đó, những hiểu biết về điện đồ ở tî̃nh mạch phổi ở bệnh nhân rung nhĩkịch phát ở Việt Nam còn rất khiêm tốn, làm ảnh hưởng đến hiệu quả điều trị ở bệnh lý này.Chính vì những lý do trên, nghiên cứu này được tiến hành với mục tiêu mô tả đặc điểm điện đồ tĩnh mạch phổi ởbệnh nhân rung nhĩ kịch phát tại Viện Tim mạch Việt Nam.

\section{II. ĐỐI TƯợNG VÀ PHƯƠNG PHÁP NGHIÊN CỨU}

1. Đối tượng nghiên cứu. Bệnh nhân được chẩn đoán xác định rung nhĩ kịch phátvà có chỉ định điều trị bằng năng lượng sóng có tần số radio theo khuyến cáo của Hội Tim mạch châu Âu (European Society of Cardiology - ESC). Bệnh nhân đồng ý tham gia nghiên cứu.

Tiêu chuẩn loại trừ: mắc bệnh lý van tim; huyết khối buồng tim; rối loạn chức năng tâm thu thất trái trung bình đến nặng $(<40 \%)$; bệnh lý cấp tính như nhiếm khuẩn cấp, tai biến mạch máu não mới, rối loạn đông máu, suy thận với mức lọc cầu thận <30 ml/phút; rung nhĩ thứ phát chưa kiểm soát được nguyên nhân như nhiễm độc, rối loạn chức nằng tuyến giáp.

\section{Phương pháp nghiên cứu}

2.1. Thiết kế nghiên cứu: mô tả cắt ngang tại Viện Tim mạch Việt Nam, Bệnh viện Bạch Mai. Thời gian nghiên cứu: từ tháng $8 / 2017$ đến tháng 9/2018.

\subsection{Mẫu nghiên cứu:}

* Cỡ mẫu nghiên cứu: nghiên cứu tiến hành ở 45 bệnh nhân.

*Chọn mẫu nghiên cứu: chọn mẫu toàn bộ. Bệnh nhân rung nhĩ kịch phát thỏa mãn các tiểu chuẩn chọn bệnh được lấy vào nghiên cứu liên tiếp theo trình tự thời gian.

2.3. Nội dung, biến sốnghiên cứu chính:

*Một số đặc trưng cá nhân: tuổi; giới tính (nam giới/nữ giới); cơn rung nhĩ: tần suất xuất hiện, thời gian mắc bệnh, điều kiện xuất hiện cợn, điều kiện kết thúc cơn.

\section{*Đặc điểm điện đồ tĩnh mạch phổi} (TMP) khi thăm dò bằng điện cực vòng

- Số lượng tĩnh mạch phổi có hoạt động điện (điện đồ).

+ Điện đồ tĩnh mạch phổi được định nghĩa là điện thể có tần số cao, có hình dạng sắc nét, thời gian $<50 \mathrm{~ms}$ và điện thế $>0,05 \mathrm{mV}$, và đi sau điện đồ cơ nhĩ [6], [7].Điện đồ tĩnh mạch phổi được xác định bằng sự biến mất của chúng sau khi tĩnh mạch phổi bị cô lập về điện học [6].

- Vị trí tĩnh mạch phổi có hoạt động điện thế: tĩnh mạch phổi trên trái, dưới trái, trên phải, dưới phải, tĩnh mạch phụ.

- Số cặp điện cực của điênn cực vòng (PV 1-2, $3-4,5-6,7-8,9-10)$ tại mối tĩnh mạch phổi có hoạt động điện.

- Thời gian dẫn truyền qua lỗ tĩnh mạch phổi: được xác định là khoảng thời gian giữa khởi đầu điện thế của tâm nhĩ (atrial deflection - A) đến điểm kết thúc điện thế tại tĩnh mạch phổi (PV potential - PV), được ký hiệu là khoảng A-PV (trong nghiên cứu không sử dụng điểm khởi đầu của điện thế tĩnh mạch phổi bởi vì khó xác định do điện thế phân mảnh hoặc liên tục)[8]. Khoảng A-PV được ghi trong khi nhịp xoang: tiến hành đo khoảng $A-P V$ tại mỗi cặp của điện cực vòng (PV 1-2, 3-4, 5-6, 7-8, 9-10) sau đó xác định giá trị trung bình và giá trị lớn nhất của 
khoảng A-PV tại mỗi tĩnh mạch phổi.

- Hình dạng điện đồ tĩnh mạch phổi: gồm điện thễ thẩp, điện thế 1 pha, 2 pha, 3 pha, nhiều thành phần và điện đồ kép [7],

\subsection{Quy trình nghiên cứu}

* Bệnh nhân được chụp cắt lớp vi tính đa dãy tĩnh mạch phổi (128 và 256 dãy) để đánh giá chính xác số lượng tĩnh mạch phổi.

*Tiến hành ghi điện đồ tĩnh mạch phổi tại phòng Cathlab

- Ghi điện đồ trước triệt đốt RF tại lỗ tĩnh mạch phổi bằng điện cực vòng lần lượt ở tĩnh mạch phổi trên trái, dưới trái, trên phải và dưới phải, và tĩnh mạch phổi phụ (nếu có), trong đó điện cực vòng 10 cực sẽ được đưa vào vị trí $5 \mathrm{~mm}$ của lỗ tĩnh mạch phổi. Điện đồ được ghi tại lỗ tĩnh mach phổi.
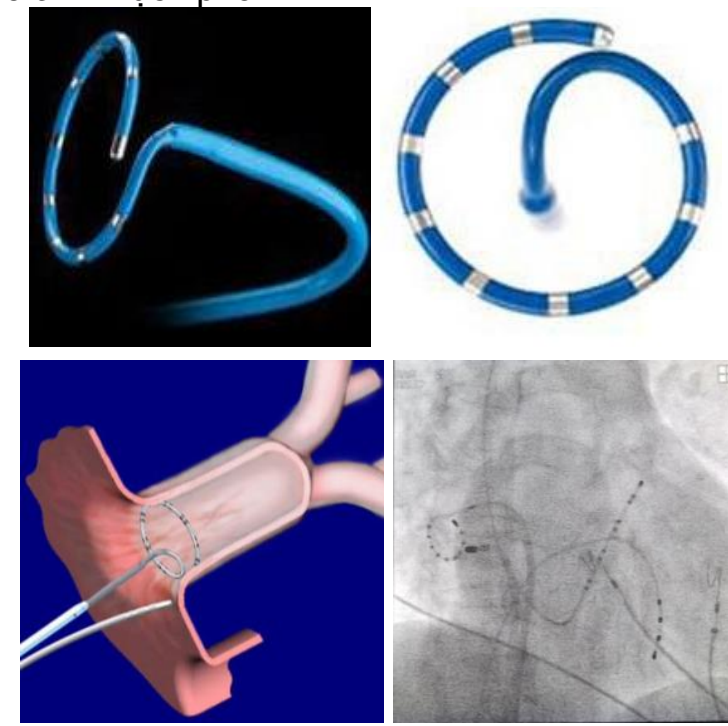

Hình 1. Hình ảnh điên cức vòng (điên cực Circular)

- Ở mỗi tĩnh mach phổi sẽ ghi nhận điện thế từ 5 cặp điện cực PV 1-2, 3-4, 5-6, 7-8, 9-10 của điện cực vòng. ở một số tĩnh mạch phổi phụ giữa phải không ghi được điện thế bởi vì ống thông không thể đưa được vào trong các lỗ TMP đó.

+ Đối với những trường hợp nhịp xoang (ngoài cơn rung nhĩ), điện thế ghi tại tînh mạch phổi khi nhịp xoang và ngay thời điểm tạo nhịp từ xoang vành với chu kỳ dài $600 \mathrm{~ms}$ hoặc 500 ms (cycle length) (tiến hành tạo nhịp từ xoang vành để xác định và phân biệt điện thế nhĩ và điện thế của tĩnh mạch phổi).

- Ghi điện đồ sau triệt đốt tại lỗ tĩnh mạch phổi bằng điện cực vòng: kiểm tra lần lượt ở tînnh mạch phổi trên trái, dưới trái, trên phải, dưới phải, tĩnh mạch phổi giữa phải.

+ Đối với những tînh mach phổi còn ghi được điện đồ nghi ngờ là điện đồ far-field đến từ tiểu nhĩ trái, thì tạo nhịp tại tiểu nhĩ trái. Nếu điện đồ thu được từ điện cực vòng đi sát với spike tạo nhịp thì đó là điện đồ far-field thu được trong tĩnh mạch phổi.

+ Tạo nhịp lần lượt từ PV 1-2 đến PV 9-10, nếu khổng thấy điện đồ dẫn ra nhĩ trái thì tĩnh mạch phổi đó đã bị cô lập hoàn toàn (Exit block).

2.4. Xử lý và phân tích số liệu: Số liệu được quản lý và phân tích trên phần mềm IBM SPSS 20.0.

2.5. Đạo đức nghiên cứu: Thực hiện theo đúng các quy định và hướng dẫn về đạo đức trong nghiên cứu y sinh học. Đối tượng nghiên cứu đã được thông báo về mục đích của nghiên cứu và hoàn toàn tự nguyện tham gia nghiên cứu.

\section{KẾT QUẢ NGHIÊN CỨU}

Bảng 1. Một số đặc trưng cá nhân của đôi tượng nghiên cứu

\begin{tabular}{|c|c|c|}
\hline Đặc trưng cá nhân & Số lượng & Tỷ lệ \% \\
\hline \multicolumn{3}{|c|}{ Giới tính } \\
\hline Nam giới & 33 & 73,3 \\
\hline Nữ giới & 12 & 26,7 \\
\hline \multicolumn{3}{|c|}{ Nhóm tuối } \\
\hline$<40$ tuối & 3 & 6,7 \\
\hline $40-49$ tuối & 8 & 17,8 \\
\hline $50-59$ tuối & 11 & 24,4 \\
\hline$\geq 60$ tuối & 23 & 51,1 \\
\hline Tuổi* & \multicolumn{2}{|c|}{$\begin{array}{l}\text { Trung vi: } 60 \text {, nhỏ nhất: } \\
26 \text {, Iớn nhất: } 75\end{array}$} \\
\hline Chiêu cao (m) & \multicolumn{2}{|c|}{$\begin{array}{c}\text { Trung bình } \pm \text { SD: } \\
1,64 \pm 0,08\end{array}$} \\
\hline Cân nặng (kg) & \multicolumn{2}{|c|}{$\begin{array}{l}\text { Trung bình } \pm \text { SD: } \\
62,20 \pm 10.04\end{array}$} \\
\hline \multicolumn{3}{|c|}{ BMI $\left(\mathbf{k g} / \mathbf{m}^{2}\right)$} \\
\hline Thiếu cân (BMI <18,5) & 1 & 2,2 \\
\hline $\begin{array}{c}\text { Bình thường } \\
(18,5 \leq \text { BMI }<23)\end{array}$ & 21 & 46,7 \\
\hline $\begin{array}{c}\text { Thừa cân } \\
(23 \leq \text { BMI }<25)\end{array}$ & 11 & 24,4 \\
\hline Béo phì $(B M I \geq 25)$ & 12 & 26,7 \\
\hline
\end{tabular}

*Phân bố không chuẩn. SD: độ lệch chuấn

Trong số 45 bệnh nhân tham gia nghiên cứu, nam giới chiếm tỷ lệ $73,3 \%$. Bệnh nhân $\geq 60$ tuổi chiếm tỷ lệ cao nhất $(51,1 \%)$; tuổi nhỏ nhất là 26 tuổi, lớn nhất là 75 tuổi.Thời gian phát hiện rung nhĩ có trung vị là 3,0 tháng, ngắn nhất là 1 tháng, dài nhất là 80 tháng. Số cơn rung nhĩ/tháng có trung vị là 4 cơn, ít nhất là 1 cơn và nhiêu nhất là 16 cơn. Trong đó $77,8 \%$ cơn rung nhĩ tự hết.

*Đặc điểm điện đồ tĩnh mạch phổi. Kết quả nghiên cứu cho thấy $80,0 \%$ bểnh nhân có 4 tînh mạch phổi có điện đồ. Trung bình tĩnh mạch phổi có điện đồ là $3,89 \pm 0,57$. 
Bảng 2. Tỷ lệ có điện đồ theo từng tĩnh mạch phôi $(n=45)$

\begin{tabular}{|c|c|c|}
\hline Điện đồ & $\begin{array}{c}\text { Số } \\
\text { lượng }\end{array}$ & $\begin{array}{c}\text { Tỷ lệ } \\
\text { \% }\end{array}$ \\
\hline TMP trên trái $(n=44)$ & 44 & 100 \\
\hline TMP dưới trái $(n=44)$ & 42 & 95,5 \\
\hline TMP trên phải $(n=45)$ & 43 & 95,6 \\
\hline TMP dưới phải $(n=45)$ & 42 & 93,3 \\
\hline Thân chung TMP trái $(n=1)$ & 1 & - \\
\hline
\end{tabular}

TMP giữa phải $(\mathrm{n}=3)^{*}$

*: Số lượng TMP giữa phải là 9, nhưng chỉ 3 trường hợp điện cực vòng đưa được vào trong tĩnh mạch phổi ghi điện đồ

Nhận xét: $100 \%$ bệnh nhân có điện đồ tại tĩnh mạch phổi (100\%). Tỷ lệ có điện đồ ởTMP trên trái là $100 \%$, dưới trái là $95,5 \%$, trên phải là $95,6 \%$ và dưới phải là 93,3\%.

Bảng 3. Khoảng A-PV tối đa và trung binh qua lỗ tĩnh mạch phổi

\begin{tabular}{|c|c|c|c|c|c|c|}
\hline Khoảng A-PV & Trên trái ${ }^{a}$ & Dưới trái b & Trên phải c & Dưới phải ${ }^{d}$ & LCT & Giữa phảie \\
\hline Số TMP & 32 & 32 & 34 & 29 & 1 & 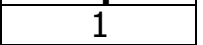 \\
\hline \multirow{2}{*}{ Tối đa (ms) } & $67,00 \pm 9,72 \mathrm{f}$ & $62,93 \pm 9,75 \mathrm{~g}$ & $64,81 \pm 9,53 \mathrm{~h}$ & $60,37 \pm 7,76 i$ & 67,00 & 56,00 \\
\hline & \multicolumn{6}{|c|}{$\mathbf{p}_{\mathrm{f}-\mathrm{g}}=\mathbf{0 , 0 0 9}, \mathrm{p}_{\mathrm{f}-\mathrm{h}}=0,060, \mathrm{p}_{\mathrm{f}-\mathrm{i}}=\mathbf{0 , 0 0 1}, \mathrm{p}_{\mathrm{g}-\mathrm{h}}=0,668, \mathrm{p}_{\mathrm{g}-\mathrm{i}}=0,768, \mathrm{p}_{\mathrm{h}-\mathrm{i}}=0,492$} \\
\hline \multirow{2}{*}{$\begin{array}{c}\text { Trung bình } \\
\text { (ms) }\end{array}$} & $56,65 \pm 8,52 \mathrm{k}$ & $48,67 \pm 13,38$ & $50,92 \pm 10,82 \mathrm{~m}$ & $49,76 \pm 8,11 \mathrm{n}$ & 57,20 & 45,00 \\
\hline & \multicolumn{6}{|c|}{$=\mathbf{0 , 0 0 2}, \mathbf{p}_{\mathrm{k}-\mathrm{n}}=\mathbf{0 , 0 0 0}, \mathrm{pl-m}=0,653, \mathrm{pl}_{\mathrm{l}-\mathrm{n}}=0,393, \mathrm{p}_{\mathrm{m}-\mathrm{n}}=0,856$} \\
\hline
\end{tabular}

a: 32 trường hợp ghi được điện đồ tai TMP trên trái; b: 32 trường hợp ghi được điện đồ TMP dưới trái, trong đó có 2 trường hợp khổng có điện đồ; c: 34 trường hợp ghi được điện đồ TMP dưới trái, trong đó có 2 trường hợp không có điện đồ; d: 29 trường hợp ghi được điện đồ TMP dưới trái, trong đó có 2 trường hợp không có điện đồ; $\mathrm{e}: 1$ trường hợp ghi được điện đồ TMP giữa phải. LCT: thân chung TMP trái.Sử dụng T-test.
Nhân xét: Khoảng A-PV tối đa qua lố TMP trên trái $(67,00 \pm 9,72 \mathrm{~ms})$ lớn hơn có ý nghĩa thống kê so với TMPdưới trái và dưới phải. Khoảng A-PV trung bình qua lỗ TMP trên trái $(56,65 \pm 8,52 \mathrm{~ms})$ là lớn nhất.

*Hình dạng điện đồ tĩnh mạch phổi: số cặp điện cực vòngghi được điện đổ khi tạo nhịp xoang vành là 645 .

Bảng 4. Hình dạng điện đồ TMP ở cặp điện cực vòng

\begin{tabular}{|c|c|c|c|c|c|}
\hline $\begin{array}{l}\text { Hình dang } \\
\text { điện đồ* }\end{array}$ & $\begin{array}{c}\text { Tống } \\
(\mathrm{n}=645)\end{array}$ & $\begin{array}{l}\text { Trên trái } \\
(\mathrm{n}=160)\end{array}$ & $\begin{array}{l}\text { Dưới trái } \\
(n=160)\end{array}$ & $\begin{array}{l}\text { Trên phải } \\
(n=170)\end{array}$ & $\begin{array}{l}\text { Dưới phải } \\
(n=155)\end{array}$ \\
\hline Không có & $9,1(6,0)$ & $1,9(2,8)$ & $15,0(5,6)$ & $11,2(3,2)$ & $8,4(2,9)$ \\
\hline 1 pha & $4,6(4,7)$ & $2,5(4,1)$ & $5,0(4,7)$ & $5,9(5,9)$ & $5,2(4,9)$ \\
\hline 2 pha & $19,4(8,4)$ & $13,1(8,9)$ & $23,8(12,0)$ & $19,4(2,6)$ & $21,3(4,9)$ \\
\hline 3 pha & $29,5(9,1)$ & $36,2(3,6)$ & $25,6(10,2)$ & $25,3(9,7)$ & $30,9(9,0)$ \\
\hline Nhiều thành phần & $31,6(8,7)$ & $34,4(10,6)$ & $23,1(7,8)$ & $35,3(5,9)$ & $33,6(5,4)$ \\
\hline Điện đồ kép & $5,8(5,9)$ & $11,9(6,8)^{1}$ & $7,5(3,6)^{2}$ & $2,9(2,9)^{3}$ & $0,6(1,4)^{4}$ \\
\hline & \multicolumn{5}{|c|}{$\mathbf{p}_{1-2}=\mathbf{0}, \mathbf{0 0 0}, \mathbf{p}_{\mathbf{1 - 3}}=\mathbf{0 , 0 0 0}, \mathbf{p}_{\mathbf{1 - 4}}=\mathbf{0 , 0 0 0} ;$ Mann - Whitney U Test } \\
\hline
\end{tabular}

*Trình bày số liệu dạng Trung bình (SD) (\%).

Hình dang điện đồ nhiều thành phần chiếm tỷ lệ cao nhất (với $31,6 \% \pm 8,7 \%$ ), tiếp đến là điện đồ 3 pha $(29,5 \% \pm 9,1 \%)$, điên đồ 2 pha $(19,4 \%$ $\pm 8,4 \%)$. Hình dạng điện đồ kép chiếm tỷ lệ $5,8 \% \pm 5,9 \%$. Hình dạng điện đồ kép gặp nhiều nhất ở TMP trên trái $(11,9 \% \pm 6,8 \%)$.

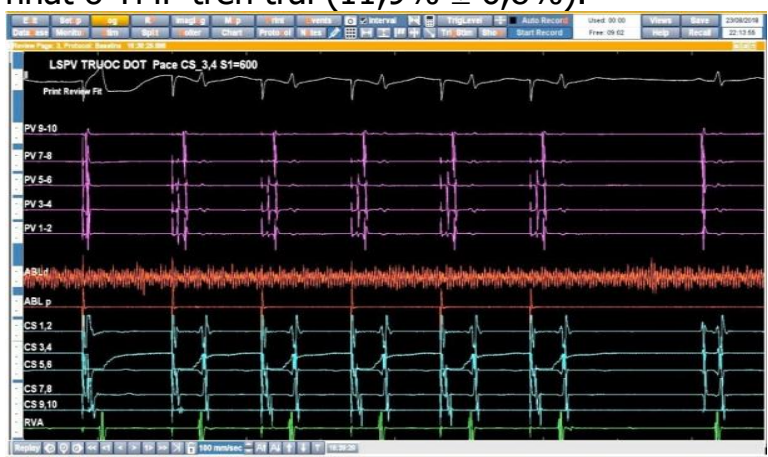

Hình 2. Hình ảnh điện đồ ghi tại tĩnh mạch phổi trên trái trước RF. Hình ảnh điện đồ tĩnh mạch phổi ở PV1-2, phía trước là điện đồ nhĩ (Bệnh nhân N.T.T 26 tuổi).

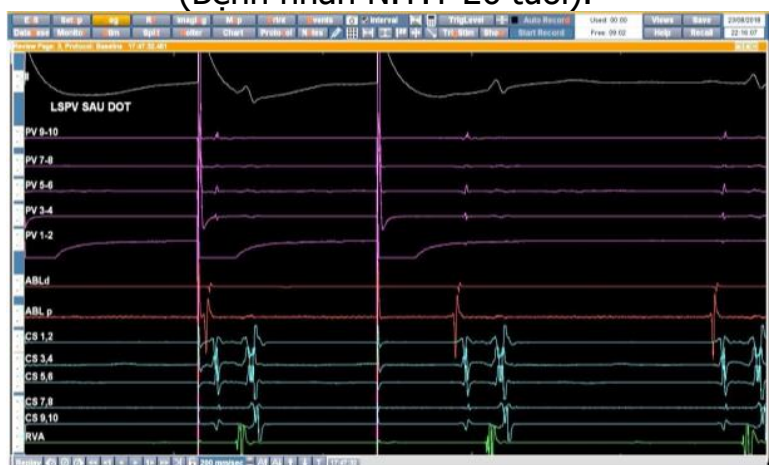

Hình 3. Hình ảnh điện đồ ghi tại tĩnh mạch phổi 
trên trái sau RF. Không còn hình ảnh điện đồ tại tĩnh mach phổi, đã kiểm tra exit block (Bênh nhân N.T.T 26 tuổi).

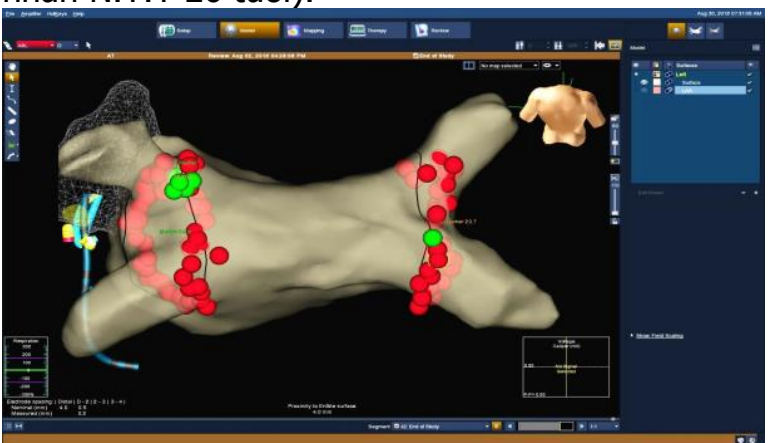

Hình 4. Hình ảnh cô lập 4 tĩnh mạch phổi ở bênh nhân. Điểm màu xanh là các điểm khi triệt đốt đã cô lập được điện đồ tại tĩnh mạch phổi tương ứng (PV isolation)(Bệnh nhân N.T.T 26 tuổi).

\section{BÀN LUÂN}

Tĩnh mạch phổi có vai trò rất quan trọng trong sinh lý bệnh của rung nhĩ. Nhiều nghiên cứu đã chỉ ra rẳng các ổ ngoại vị ở tĩnh mạch phổi có thể là trung tâm khởi phát rung nhĩ [8]. Một số nghiên cứu khác cho thấy, tĩnh mạch phổi không chỉ là ổ khởi phát rung nhĩ mà còn tham gia độc lập vào duy trì rung nhĩ.Điện đồghi tại tĩnh mạch phổi gồm ít nhất 2 thành phần; trong đó, thành phần đầu tiên là điện đồ far-field, tiếp theo là điện đồ của tĩnh mạch phổi sau một thời gian đẳng điện. Điện đồ tĩnh mạch phổi được định nghĩa là điện thế có tần số cao, có hình dạng sắc nét, thời gian $<50 \mathrm{~ms}$ và điện thế $>0,05$ $\mathrm{mV}$, và đi sau điện đồ nhĩ trái [4], [5]. Điện đồ tĩnh mạch phổi được xác định bằng sự biến mất của chúng sau khi tĩnh mạch phổi bị cô lập về điện học[4]. Tất cả bệnh nhân đều có điện đồ tại tĩnh mạch phổi (100\%). Đa số bệnh nhân có 4 tĩnh mạch phổi có điện đồ (chiếm tỷ lệ 80,0\%). Kết quả của tác giả Eva Hertervig cho thấy, có 91,0\% tĩnh mạch phổi ở bệnh nhân rung nhĩ được ghi nhận có hoạt động điện thế, trong khi đó ở bệnh nhân không rung nhĩ thì tỷ lệ này là thấp hớn nhiều với 11,0\% tĩnh mạch phổi [6]. Theo Wendel Moreira (2008), tiến hành ở 70 bệnh nhân rung nhĩ kịch phát, đã phát hiện hầu hểt các ổ khởi phát rung nhĩ xuất phát từ tĩnh mạch phổi. Hoạt động điện ở tĩnh mạch phổi trền trái được phát hiện ở 63 bệnh nhẩn chiếm tỷ lệ 90,0\%, ở tĩnh mạch phổi dưới trái là 52 bệnh nhân chiếm $74,3 \%$, ở tĩnh mạch phổi trên phải là 57 bệnh nhân chiếm $81,4 \%$ và ở tĩnh mạch phổi dưới phải là 16 bệnh nhân chiếm 22,9\% [3]. Theo kết quả của Hiroshi Tada, tỷ lệ tĩnh mạch phổi bên trái có điện đồ chiếm 64,0\%, tĩnh mạch phổi trên phải có điện đồ chiếm 95,0\%[4]. Ở tĩnh mạch phổi trên phải, các điện thế nhĩ nhỏ hơn nhiểu so với điện thế tĩnh mach phổi, và có rất ít chồng chéo giữa các điện thế trong lúc nhịp xoang. Vì vậy, thường không khó để phân biệt điện thế nhĩ và điện thế trong tĩnh mạch phổi trên phải. Trong khi đó, ở tĩnh mạch phổi trên trái và dưới trái, cân thiết tạo nhịp xoang vành để phân tách điện đồ nhĩ và điện đồ tĩnh mạch phổi. Trong 2 tĩnh mạch này, điện thế nhĩ và tĩnh mạch phổi có thể có biên độ tưởng tự nhau, có $65 \%$ có sự chồng chéo giữa 2 điện thế này ngay cả trong khi tạo nhịp xoang vành. Trong trường hợp này, tạo nhịp tiểu nhĩ trái có thể giúp xác định rõ điện thế tĩnh mạch phổi.

Điện đồ tĩnh mạch phổi được ghi nhận tại lỗ tĩnh mạch phổi, và dần truyền chậm quanh lỗ tĩnh mạch phổi có thể đóng vai trò khởi phát và duy trì rung nhĩ [6]. Theo đồng thuận của HRS/EHRA/ECAS, cô lập hoàn toàn điện thế hoạt động ở tĩnh mạch phổi là mục tiêu điều trị trong rung nhĩ, đặc biệt là rung nhĩ kịch phát. Điện thế tĩnh mạch phổi thường xuất hiện như là điện thế tai chỗ đi theo sau điên thế nhĩ sau một thời gian trễ. Đôi khi, điện thế đó khởi phát nhanh, liên tục, với nhiều hoạt động điện phân mảnh mà không có sự tách biệt giữa điện thế nhĩ và tĩnh mach phổi. Đó có thể là điê̂n thế môt pha, hai pha hoăc ba pha được ghi nhận tại lỗ tĩnh mạch phổi, và không có sự phân biệt rõ̉ ràng với điện thế nhĩ. Các nghiên cứu cho thấy có khoảng trễ nhất đinh trong dẫn truyền từ nhĩ đến tĩnh mạch phổi ở bệnh nhân rung nhĩ;nguyên nhân là dohoạt động điện học ở tĩnh mạch phổi khởi phát và duy trì cớn rung nhĩ, bên canh đó, có thể do các vòng vào lại có nguồn gốc từ lỗ tĩnh mach phổi [7]. Tác giả Jais và cộng sự cũng cho rẳng thời gian dẫn truyền nhĩ trái đến tĩnh mạch phổi ở bệnh nhân rung nhĩ lớn hơn so với không rung nhĩ, đồng thời thời gian trơ ngắn hơn, do đó tao điều kiện thuận lợi cho vòng vào lại ở bên trong và quanh lỗ tî̃nh mạch phổi. Kết quả nghiên cứu này cho thây, hình dạng điện đồ nhiêu thành phần chiếm tỷ lệ cao nhất (với $31,6 \% \pm 8,7 \%$ ), tiếp đến là điện đồ 3 pha $(29,5 \% \pm 9,1 \%)$, điện đồ 2 pha $(19,4 \% \pm 8,4 \%)$, trong đó điện đồ kép chiếm $5,8 \% \pm 5,9 \%$. Theo Dipen Shah, trong lúc nhịp xoang ở bệnh nhân rung nhĩ phát hiện được $100 \%$ tĩnh mạch phổi trên trái có điện đồ kép, $80 \%$ tĩnh mạch phổi dưới trái có điện đồ kép, $23 \%$ tĩnh mạch phổi trên phải có điên đồ kép và $100 \%$ tĩnh mạch dưới phải có điện đờ đơn. Trong khi đó, theo nghiên cứu của $\mathrm{E}$. Hertervig, ở bệnh 
nhân không rung nhĩ, điện đồ ghi được tại tĩnh mạch phổi chủ yếu là các điện thế 1 pha, hai pha hoặc 3 pha, có các hoạt động điện thế hẹp khổng có sự phân tách rõ ràng với hoạt động điện từ nhĩ [6]. Theo tác giả Milad El Haddad (2015) cho thây, sau khi cô lập tĩnh mạch phổi thì ở bệnh nhân rung nhĩ vẫn còn điện đồ tại tĩnh mạch phổi, tuy nhiên hình dạng điện đồ đã có nhiều thay đổi: trước cô lập chủ yếu là điện đồ 3 pha, nhiều thành phần và điện đồ kép, còn sau cô lập tĩnh mạch phổi thì điện đồ chủ yếu đơn giản và ít thành phần hơn[7].

\section{KẾT LUẬN}

Kết quả nghiên cứu cho thấy,cácbệnh nhân rung nhĩ kịch phát đềucó điện đồ tại ít nhất một tĩnh mạch phổi (chiếm 100\%), trong đó $80 \%$ bệnh nhân có cả 4 tĩnh mạch phổi có điện đồ.Khoảng thời gian dẫn truyền nhĩ - tĩnh mạch phổi (khoảng A-PV) tối đa và trung bình ở tî̃nh mạch phổi trên trái là dài nhất $(67,00 \pm 9,72 \mathrm{~ms}$ và $56,65 \pm 8,52 \mathrm{~ms}$, tương ứng). Hình dạng điện đồ tĩnh mạch phổi thường gặp là điện đồ nhiểu thành phần $(31,6 \% \pm 8,7 \%)$. Điện đồ kép chiếm tỷ lệ $5,8 \% \pm 5,9 \%$, trong đóhình dạng điện đồ kép gặp nhiều nhất ở tĩnh mạch phổi trên trái $(11,9 \% \pm 6,8 \%)$.

\section{TÀI LIÊU THAM KHẢO}

1. Chugh S.S., Havmoeller R., Narayanan K., et al (2014). Worldwide Epidemiology of Atrial Fibrillation: A Global Burden of Disease 2010 Study. Circulation, 129(8), 837-847.

2. Snoer A.H., Ellemann $K_{\text {., }} \&$ Wienecke $T$. (2014). High Prevalence of Paroxysmal Atrial Fibrillation in A Selected Population of Patients with Stroke and Transient Ischemic Attack, 5.

3. Moreira W., Manusama R., Timmermans $\mathbf{C}_{\text {. }}$ et al (2008). Long-term follow-up after cryothermic ostial pulmonary vein isolation in paroxysmal atrial fibrillation. Journal of the American College of Cardiology, 51(8), 850-855.

4. Tada H., Oral H., Greenstein R., et al (2002) Differentiation of atrial and pulmonary vein potentials recorded circumferentially within pulmonary veins. Journal of cardiovascular electrophysiology, 13(2), 118-123.

5. Haïssaguerre M., Shah D.C., Jaïs $P_{\text {., }}$ et al (2000). Electrophysiological breakthroughs from the left atrium to the pulmonary veins. Circulation, 102(20), 2463-2465.

6. Hertervig E., Kongstad O., Ljungstrom E., et al (2008). Pulmonary vein potentials in patients with and without atrial fibrillation. Europace, 10(6), 692-697.

7. El Haddad M., Houben R., Berte B., et al (2015). Bipolar electrograms characteristics at the left atrial-pulmonary vein junction: Toward a new algorithm for automated verification of pulmonary vein isolation. Heart Rhythm, 12(1), 21-31.

8. Haissaguerre M., Jaïs P., Shah D.C., et al (1998). Spontaneous initiation of atrial fibrillation by ectopic beats originating in the pulmonary veins. New England Journal of Medicine, 339(10), 659-666.

\title{
ĐĂC ĐIỂM LÂM SÀNG VÀ TÌNH HÌNH ĐỀ KHÁNG KHÁNG SINH TRÊN BỆNH NHÂN CHỐC TẠI BỆNH VIỆN DA LIỄU THÀNH PHỐ CẦN THO' NĂM 2020
}

\author{
Trần Nguyễn Anh Thu*, Huỳnh Văn Bá*, \\ Nguyễn Thị Thùy Trang*, Lạc Thị Kim Ngân*, Phạm Thanh Thảo*
}

\section{TÓM TẮT}

Mục tiêu: Mô tả đặc điểm lâm sàng và tình trạng kháng thuốc của các vì khuẩn nhiếm trên bệnh nhân chốc đến khám tại bệnh viện Da Liễu TP. Cần Thơ từ 06/2020 - 12/2020. Đối tượng và phương pháp: Mô tả cắt ngang trên mẫu là 55 bệnh nhân, được lấy bệnh phẩm sang thương trên da, nuôi cấy và̀ làm kháng sinh đồ. Kết quả: 35 trường hợp bệnh nhân bị chốc có kết quả cây vi khuẩn dương tính $(63,6 \%)$.

*Trường Đại học Y Dược Cần Thơ Chịu trách nhiệm chính: Trần Nguyễn Anh Thư Email: trannguyenanhthu.y39@gmail.com Ngày nhận bài: 15/6/2021

Ngày phản biện khoa học: 14/7/2021

Ngày duyệt bài: 15/8/2021
Trong số này, chốc không bóng nước là $61,8 \%$, chốc bóng nước là $25,5 \%$ và chốc loét là $12,7 \%$. Đa số vi khuẩn phân lập được là S.aureus (93,8\%). Tỉ lệ S.aureus kháng với penicillin và erythromycin là $100 \%$, kháng với amoxicillin/acid clavulanic là $93,5 \%$, còn nhạy với cefuroxime, oxacillin, tetracyclin, ciprofloxacin, levofloxacin, linezolid và vancomycin, có 2 trường hớp kháng với vancomycin thuộc thể chốc loét. Tỉ lệ chủng tụ câu vàng kháng methicillin (MRSA) được phát hiện trong nghiên cứu là $87,1 \%$. Và cả 3 ca cây ra S.pyogenes (chiếm 8,6\%) vẫn còn nhay với penicillin. Kết luận: Chốc không bóng nước là thể bệnh thường găp nhất trên lâm sàng. Tác nhân gây bênh chủ yếu làs.aureus, gần nhữ kháng toàn bộ với penicillin, erythromycin, và vẫn còn nhay cao với oxacillin, cefuroxime và vancomycin. Tư khóa: Chốc, kháng kháng sinh, S.aureus, S. pyogenes. 